\title{
PENATAAN RUANG PAMER KERAJINAN KERAMIK DINOYO MALANG
}

\author{
Noviani Suryasari' ${ }^{1}$, Triandriani Mustikawati², Ema Yunita Titisari ${ }^{3}$ \\ 1,2,3 Fakultas Teknik, Universitas Brawijaya \\ email: noviani@ub.ac.id
}

\begin{abstract}
Dinoyo ceramic village located on Jl. MT Haryono Dinoyo District of Dinoyo is a center of home industry economic activity, announced by the Government of the tourist village of Malang. Industrial products are produced is in the form of ceramics, with a wide variety of forms such as pottery items for decoration, various souvenirs to household appliances/ kitchen. On the one hand, the potential for the development of economic activities of the people of the industry is still quite large visible from a good level of marketing, not only in the city of Malang, but even out of town or country. But on the other hand, problems arise in the aspect of the promotion strategy that is not supported by quality of showroom with attractive layout concepts. Based on three deficiencies can be identified from the management arrangement ceramics Dinoyo showrooms are associated with: (1) space zoning (2) arrangement of physical elements of space and (3) arrangement of handicrafts, the community service is targeted to structuring concept showroom ceramics. Structuring concept was applied in the field by applying spatial organization in a more effective, and the provision of furniture in accordance with the character of the object to show off.
\end{abstract}

Keywords: showrooms, ceramic

\section{Pendahuluan}

Kampung wisata keramik Dinoyo memiliki produk andalan keramik dengan spesifikasi karakter kerajinan yang berbeda dengan produk kerajinan keramik di kota lain seperti Kasongan (Yogyakarta). Kegiatan promosi guna memperkenalkan lebih dekat ragam jenis kerajinan keramik antara lain adalah dengan pelaksanaan Festival Keramik Dinoyo yang dilakukan setahun sekali. Namun penyelenggaraannya belum ditunjang dengan kondisi fasilitas yang memadai, termasuk kondisi ruang pamer yang masih kurang representatif sebagai media promosi produk secara rutin setiap harinya, tidak hanya pada acara-acara promosi yang khusus seperti festival tersebut di atas. Padahal ruang pamer (showroom) sangat menunjang penjualan produk dan peningkatan produktivitas. Teknik penataan produk juga perlu diperhatikan agar lebih menarik sehingga menunjang tingkat penjualan produk.

Gambaran umum untuk ruang pamer kerajinan keramik Dinoyo, rata-rata memiliki kekurangan-kekurangan dalam hal manajemen ruang sebagai berikut:

1. Pembagian ruang

Secara umum ruang pamer dibagi menjadi beberapa area menurut aktivitas yang dilakukan. Areabagian depan terutama didominasi oleh ruang untuk meletakkan 
barang-barang yang dijual ataucontoh-contoh produk kerajinan keramik yang dapat dipesan. Aktivitas yang sering dijumpaiadalah aktivitas dari pengunjung yang sedang melihat-lihat berbagai jenis barang kerajinankeramik. Sedangkan area belakang ruang dipakai untuk meletakkan barang-barang stok lama ataukemasan kardus-kardus barang-barang pesanan yang siap diambil, atau untuk aktivitaspenyelesaian transaksi/ pembayaran antara pembeli dan penjual.

Kedua area tersebut tidak terpisah secara permanen karena hanya dibatasi oleh elemen-elemen ruang yang bersifat semi-fixed (berupa perabot seperti rak atau lemari, dan meja). Antara ruang pamer dengan bagian luar dan ruang lain yang ada di sebelah dalam dari bangunan dipisahkan dengan elemen ruang yang lebih permanen berupa dinding dan pintu atau jendela. Secara umumdinding bagian depan yang membatasi ruang dalam dengan ruang luar didominasi oleh bukaan berupa jendela permanen. Namun ada pula bentuk pembatas yang tidak berupa dinding, yaituberupa elemen bukaan yang bisa dibuka dan tutup secara keseluruhan (digeser ke arah atas-bawah),sehingga yang dipakai untuk membatasi ruang dalam dan ruang luar adalah semi-fixed element yaitu rak atau lemari kaca. Secara visual kedua ruang ini masih berhubungan, sehingga pemandangan tak sedap berupa tumpukan barang pesanan mengganggu keindahan yangseharusnya muncul di area ruang pamer.

2. Penataan dan elemen fisik ruang

Terdapat elemen-elemen fisik pembatas ruang berupa fixed element (pintu, jendela, dinding) dansemi-fixed element (perabot rak, lemari, dll). Selain berfungsi sebagai pemisah antar area,sebenarnya fungsi utama dari elemen ruang berupa semi-fixed element tersebut adalah sebagai media penyajian barang-barang kerajinan. Secara fungsional, yaitu sebagai tempat meletakkan dan menata barang kerajinan yang akan dijual, rak atau lemari terdiri dari bentuk yang terbukadan tertutup (rak/lemari kaca). Jenis ukuran bermacam-macam, dengan panjang, lebar dan tinggiyang bervariasi. Peletakan rak terutama pada sisi sepanjang dinding ruang, selain ada juga yang terdapat pada bagian tengah ruang. Jarak antara rak satu dengan rak yang lain sering terlihat sangat dekat, diakibatkan salah satunya oleh keterbatasan ruang dan kuantitas produk kerajinan yang diletakkan pada ruang sehingga ruang gerak baik untuk sirkulasi maupun untuk menjangkau/ mengambil barang yang akan dilihat lebih dekat, menjadi sempit dan tidak leluasa. Ruang diantara rak juga sering dimanfaatkan untuk meletakkan barang-barang yang secara sengaja memang tidak dipamerkan karena merupakan kemasan yang telah siap diambil oleh pemesan. Keberadaan jenis barang ini akan diuraikan secara lebih detail pada bagian ketiga dibawah ini.

3. Penataan barang kerajinan

Barang kerajinan yang terdapat di dalam ruang pamer dapat dikategorikan menjadi 3 yaitu barang-barang yang diletakkan di dalam rak terbuka dan lemari kaca sebagai barang kerajinan yang disajikan bagi para pengunjung yang sedang melihatlihat atau memilih jenis produkyang akan dibeli atau dipesan. Barang-barang tersebut pada umumnya adalah jenis yang terbaru atau relatif belum lama diproduksi. Kategori yang kedua adalah barang-barang yang sudah cukup lama diproduksinya atau barang-barang stok lama, yang juga diletakkan di rakterbuka atau lemari kaca, atau yang hanya diletakkan menumpuk pada sudut-sudut ruangtertentu. Kategori yang ketiga adalah barang-barang pesanan yang disimpan dalam bentukkemasan-kemasan kardus, diletakkan di atas permukaan lantai 
dengan tatanan yangcenderung tidak rapi dan teratur pada bagian tertentu sedikit di bagian belakang ruang.Namun tidak jarang dijumpai pula peletakan barangbarang pesanan yang siap diambil oleh pemesannya itu diletakkan begitu saja pada area utama pamer di bagian depan. Tidak dijumpainya elemen perabot berupa lemari yang dapat dipergunakan untuk menyimpan secara permanen barangbarang stok lama atau secara sementara barang-barang pesanan secara lebih teratur sehingga keberadaan barang-barang yang terlihat berantakan tersebut cukup mengganggu tampilan visual ruang pamer secara keseluruhan.

Ketidakteraturan tersebut mengakibatkan ketidaknyamanan bagi pengunjung toko karena aktivitas melihat-lihat dan memilih barang menjadi terganggu ketika harus dihadang oleh kemasan-kemasan kardus sehingga memperbesar jarak pandang dan jarak jangkau kebarang yang disajikan di dalam rak. Dengan demikian tingkat keleluasaan dalam memilih menjadi berkurang. Kondisi ini semakin diperburuk pada masa-masa ramai pesanan karena kebutuhan ruang untuk penempatan barang-barang pesanan otomatis semakin bertambah.

Tingkat kenyamanan memilih barang yang kurang tersebut juga disebabkan oleh penataanyang kurang terorganisir dengan baik, sehingga ada jenis-jenis produk yang saling tumpangtindih jenisnya satu sama lain. Pengelompokan barang pada rak atau lemari tidak jelas antarajenis yang satu dengan jenis yang lain, bahkan seringkali bercampur menjadi satu.

Manajemen (penataan) ruang pamer yang tidak sesuai dengan fungsinya di atas pada dua buah toko keramik yaitu Toko Keramik Denis Souvenir dan Irama Baru sebagai kasus yang diambil pada studi ini, sangat mempengaruhi aspek produksi. Produktivitas akan sangat mungkin meningkat lebih banyak apabila manajemen ruang pamernya mendukung. Ruang pamer merupakan ujung tombak bagi kegiatan produksi keramik. Teknik dan metoda penataan ruang pamer yang tepat merupakan bagian dari strategi pemasaran.

\section{Tinjauan Pustaka}

Beberapa teori dan referansi pustaka yang menjadi dasar penyelesaikan permasalahan yang terjadi pada ruang pamer adalah:

a. Teori tata ruang pamer yang sesuai dengan kriteria (Ching, 2007; De Chiara, 1980; Dean, 1996; Neufert, 2012) :

- Fleksibilitas ruang

Fleksibilitas penggunaan ruang adalah suatu sifat kemungkinan dapat digunakannya sebuah ruang untuk bermacam-macam sifat dan kegiatan, dan dapat dilakukannya pengubahan susunan ruang sesuai dengan kebutuhan tanpa mengubah tatanan bangunan

- Sirkulasi

Sirkulasi merupakan aspek terpenting dalam perancangan ruang pamer karena terkait dengan kenyamanan pengunjung.Alur sirkulasi dapat dibayangkan sebagai benang yang menghubungkan ruang-ruang sehingga saling berhubungan (Ching, 2007). Pengarahan sirkulasi dapat dilakukan agar kegiatan pameran dapat dilakukan dan dapat berjalan lebih menarik

- Penghawaan

Perlu adanya ventilasi udara yang cukup untuk ruangan yang tidak menggunakan penghawaan buatan.Penggunaan ventilasi silang sangat penting 
agar sirkulasi udara dapat mengalir dengan baik. Ketentuan dalam penerapan ventilasi silang, yaitu lubang penghawaan minimal 5\% dari luas lantai dan udara yang mengalir masuk sama dengan volume udara yang mengalir keluar ruangan

- Pencahayaan

Pencahayaan merupakan salah satu faktor penting dalam keberhasilan tata display objek pamer. Pencahayaan diatur agar tidak mengganggu koleksi maupun menyilaukan pengunjung. Penggunaan cahaya buatan dapat lebih memberikan efek yang lebih bagus jika dibandingkan dengan pencahayaan alami, namun efek pencahayaan alami dapat memberi kesan lebih hidup. Pemasangan lampu harus diperhatikan dan terlindung agar tidak ada sumber cahaya langsung yang terlihat oleh pengunjung, yang dapat menyilaukan pengunjung

- Penataan objek pamer dan penyajian dalam ruang

Terkait dengan penataan objek pamer, ada tiga penataan objek, yaitu:

i. In showcase: benda yang dipamerkan termasuk kecil, karenanya diperlukan wadah atau kotak tembus pandang yang kadang juga memperkuat kesan/tema dari benda yang dipamerkan

ii. Free standing on the floor, on plinth or support: Benda yang dipamerkan memiliki dimensi yang cukup besar sehingga memerlukan panggung/ ketinggian tertentu untuk batas dari objek pamer

iii. On walls or panel: Benda yang dipamerkan di dinding ruang atau partisi pembatas ruangan.

Penataan objek pamer pada ruang pamerakan mempengaruhi kenyamanan pengunjung dalam mengamati objek yang dipamerkan. Penataan ruang pamer disesuaikan dengan objek yang dipamerkan antara lain besar kecilnya dimensi objek.

b. Sesuai dengan penelitian yang pernah dilakukan yaitu penelitian tentang model penataan ruang rumah produktif untuk peningkatan kegiatan ekonomi industri keramik rakyat di Dinoyo Malang (Santoso, et.al., 2012):

- Merancang ruang yang fleksibel, yaitu ruang yang mempunyai versatilitas tinggi

- Menyediakan perabot yang mendukung kegiatan

- Memperjelas area fungsional ruang

- Menyesuaikan dimensi ruang dengan ruang gerak-aktifitas

- Menyesuaikan susunan ruang dengan proses alur kegiatan

- Kejelasan antara zona area fungsional ruang dengan area sirkulasi

\section{Metode Penelitian}

Metode yang digunakan dalam penelitian ini adalah metode evaluatif-deskriptif dalam menilai kondisi ruang pamer eksisting dengan variabel evaluasi: fleksibelitas ruang, estetika, pencahayaan, penghawaan, sirkulasi, dan penataan obyek pamer. Selanjutnya disusun konsep penataan berdasarkan hasil evaluasi. Tahap-tahapnya adalah sebagai berikut:

a. Mengevaluasi penggunaan ruang-ruang di kedua toko keramik berdasarkan kriteria desain ruang pamer yang baik

b. Menyusun konsep desain penataan ruang pamer kerajinan keramik sesuai dengan penggunaan ruang dan perabot ruang

c. Merancang ruang pamer berdasarkan konsep desain yang telah ditetapkan 
d. Mengaplikasikan hasil rancangan terutama perabot ruang yaitu dengan pembuatan rak display barang kerajinan keramik sesuai dengan karakter objek pamer

\section{Hasil dan Pembahasan}

\subsection{Hasil Analisis Ruang Pamer pada Toko Keramik Denis Souvenir dan Irama Baru}

\section{a. Aspek Fleksibilitas Ruang}

Ruang pamer tidak hanya digunakan sebagai tempat berjualan produk keramik/ gips tetapi juga digunakan sebagai tempat mengerjakan proses produksinya (terutama tahap finishing). Dengan demikian maka perlu adanya pertimbangan aspek fleksibilitas ruang karena ruang pamer bersifat multifungsi. Keterbatasan luas ruang menjadi faktor yang sangat mempengaruhi kenyamanan aktivitas yang bermacam-macam tersebut, karena menjadikan ruang gerak terbatas. Di satu sisi membutuhkan ruang yang nyaman bagi pengunjung (kecukupan ruang sirkulasi dan ruang gerak bagi pengunjung) ketika melihat-lihat objek pamer, dan di sisi yang lain membutuhkan ruang yang nyaman pula bagi pemilik/ karyawan toko ketika sedang mengerjakan penyelesaian barang kerajinan keramik/ gips.

Ruang gerak bagi pengunjung menjadi terbatas karena jarak antara rak dengan posisi tubuh pengunjung relatif sempit. Sempitnya ruang gerak tersebut disebabkan karena terjadi penumpukan barang yang tidak tertata dengan baik sehingga ruang efektif untuk penyimpanan barang menjadi tidak tercapai dan mempengaruhi ruang efektif dari ruang gerak pengunjung. Selain itu, perabot yang digunakan untuk mengerjakan proses finishing oleh pemilik toko kurang mempertimbangkan ukuran yang sesuai sehingga memakan ruang gerak efektif bagi pengunjung terutama yang akan melihat objek pamer pada rak sisi sebelah dalam (selatan). Hal tersebut berpengaruh pula terhadap jarak pandang yang kurang sesuai, karena terlalu dekat untuk melihat barang di rak sebelah utara dan timur, dan terlalu jauh untuk melihat barang di rak sebelah selatan.

Tidak dapat dihindari bahwa aktivitas finishing produk terjadi pada ruang yang sebenarnya memiliki fungsi utama sebagai ruang pamer. Oleh sebab itu aktivitas finishing tetap harus diwadahi dan diupayakan dapat senyaman mungkin, sehingga terkait pula dengan kesesuaian perabot yang digunakan. Dalam hal ini, perabot meja yang digunakan adalah meja dengan tinggi berukuran rendah, yang sesuai untuk posisi duduk di ketinggian cukup rendah pula. Posisi tersebut dirasakan kurang nyaman, karena dalam waktu relatif lama, dapat berakibat cepatnya rasa capek yang muncul. Padahal untuk penyelesaian di masa-masa tingkat pemesanan tinggi, pekerjaan harus dilakukan dari sejak pagi sampai dengan sore hari.

\section{b. Aspek Sirkulasi}

Masih terkait dengan kondisi di atas yaitu tentang dua macam aktivitas yang terjadi yaitu yang dilakukan oleh pengunjung dan pemilik toko, maka area sirkulasi bagi pengunjung menjadi terhalang ketika akan melihat bahkan mengambil barang di salah satu rak yang ada di salah satu sisi ruang, karena ruang sirkulasi terpakai oleh pemilik untuk mengerjakan proses finishing. Ruang sirkulasi menjadi tidak nyaman pula karena tumpukan barang menghambat gerak sirkulasi sepanjang sisi rak. Sirkulasi di area pintu masuk juga terganggu karena adanya rak yang berada 
persis di depan pintu, dan adanya kardus-kardus yang berserakan di samping bangunan.

\section{c. Aspek Penghawaan}

Selain pintu yang menjadi media masuknya aliran udara dari luar bangunan ke dalam ruang, terdapat ventilasi pada sisi atas dinding atau tepat di sebelah atas rak pamer. Namun karena keterbatasan ruang, dimensi dinding pada ke empat sisi ruang telah dominan dipenuhi oleh perabot rak yang menempel pada dinding tersebut, sehingga hanya tersisa sedikit saja bidang dinding untuk ventilasi, dan mengakibatkan dimensi bukaan untuk masuknya udara sangat kecil. Dengan demikian penghawaan pada ruang pamer ini menjadi relatif kurang baik karena kuantitas bukaan yang tidak sebanding dengan luas dinding secara keseluruhan.

\section{d. Aspek Pencahayaan}

Pencahayaan pada ruang dominan menggunakan pencahayaan alami, karena selain memang jam buka toko ini tidak sampai malam hari, juga karena kualitas pencahayaan dalam ruang sudah tercapai lewat bidang-bidang kaca transparan yang ada di sisi-sisi dinding ruang. Penempatan kaca diintegralkan dengan bentuk rak yang digunakan, sehingga kaca juga berfungsi sebagai elemen ruang yang dapat memvisualisasikan objek pamer bagi orang yang berada di luar bangunan. Dengan demikian macam-macam produk kerajinan keramik yang dijual dapat dilihat dari luar, tidak terbatas dapat dilihat dari dalam bangunan saja.

\section{e. Aspek Estetika}

Rata-rata industri rumah tangga skala kecil, mengabaikan aspek estetika dalam desain ruang pamernya. Terlebih lagi apabila ruang pamer tersebut merangkap juga sebagai ruang untuk kegiatan yang lain. Hal ini berbeda sekali dengan yang ditemukan pada galeri yang khusus menjual produk kerajinan atau kesenian. Hal inilah yang ditemukan pada ruang pamer kerajinan keramik Dinoyo, khususnya pada obyek kasus. Ruang pamer yang merangkap pula sebagai ruang kerja abai terhadap aspek estetika. Dinding, lantai, dan plafon yang mengalami kerusakan tidak segera diperbaiki. Bahkan pada toko Irama Baru, lantai toko terlihat kotor karena percikan cat dan debu.

\section{f. Aspek Penataan Objek Pamer}

Hal terakhir yang paling penting dalam kriteria desain ruang adalah aspek penataan/ penyajian dari objek pamernya sendiri. Penataan ini kaitannya sangat erat dengan aspek estetika, karena keteraturan dan kerapihan peletakan objek pamer sangat berpengaruh pada indah atau tidaknya ruang pamer, dan sedap atau tidak sedapnya objek pamer dipandang oleh pengunjung. Pada kondisi eksisiting, rak yang digunakan untuk meletakkan barang kerajinan adalah rak berukuran tinggi 2 meter dan panjang 2,5 meter, diletakkan di sepanjang dinding ruang dengan ketinggian $80 \mathrm{~cm}-1$ meter di atas permukaan lantai (batas bawah rak) dan 2,5 $\mathrm{m}$ dari permukaan lantai (batas atas rak). Kondisi tersebut mengakibatkan barang kerajinan yang diletakkan pada bagian teratas rak masih cukup dapat dijangkau dengan tangan manusia. Sedangkan untuk dapat dilihat dengan nyaman, jarak pandang yang ada masih belum dapat memenuhi, artinya adalah masih 
dibutuhkan ruang yang cukup lebar di depan rak bagi pengunjung untuk berdiri, melihat dan menjangkau barang kerajinan dengan nyaman dan leluasa. Terkait dengan kategori barang kerajinan yang dihasilkan dan bagaimana kategori tersebut disajikan, kondisi eksisting yang ada belum menunjukkan bahwa peletakan barang sudah berdasarkan kategori tersebut, baik dari jenis maupun ukurannya. Hal tersebut mengakibatkan tidak adaanya pola keteraturan yang baik, dan berakibat pula kemudian pada tingkat kerapiannya.

\subsection{Konsep Penataan Ruang Pamer pada Toko Keramik Denis Souvenir dan Irama Baru}

Secara keseluruhan, elemen-elemen fisik pembentuk ruang pamer yang diperbaiki adalah: dinding bagian luar bangunan, dinding bagian dalam ruang, lantai ruang dalam, plafon ruang dalam. Sedangkan perbaikan yang terkait dengan penataan objek pamer adalah: pembuatan rak, pembuatan kemasan penyimpanan barang, pembuatan meja dan kursi. Secara detail dapat dilihat pada tabel dan ilustrasi berikut ini

Tabel 1. Perbaikan Ruang Pamer pada Kedua Toko Keramik Dinoyo

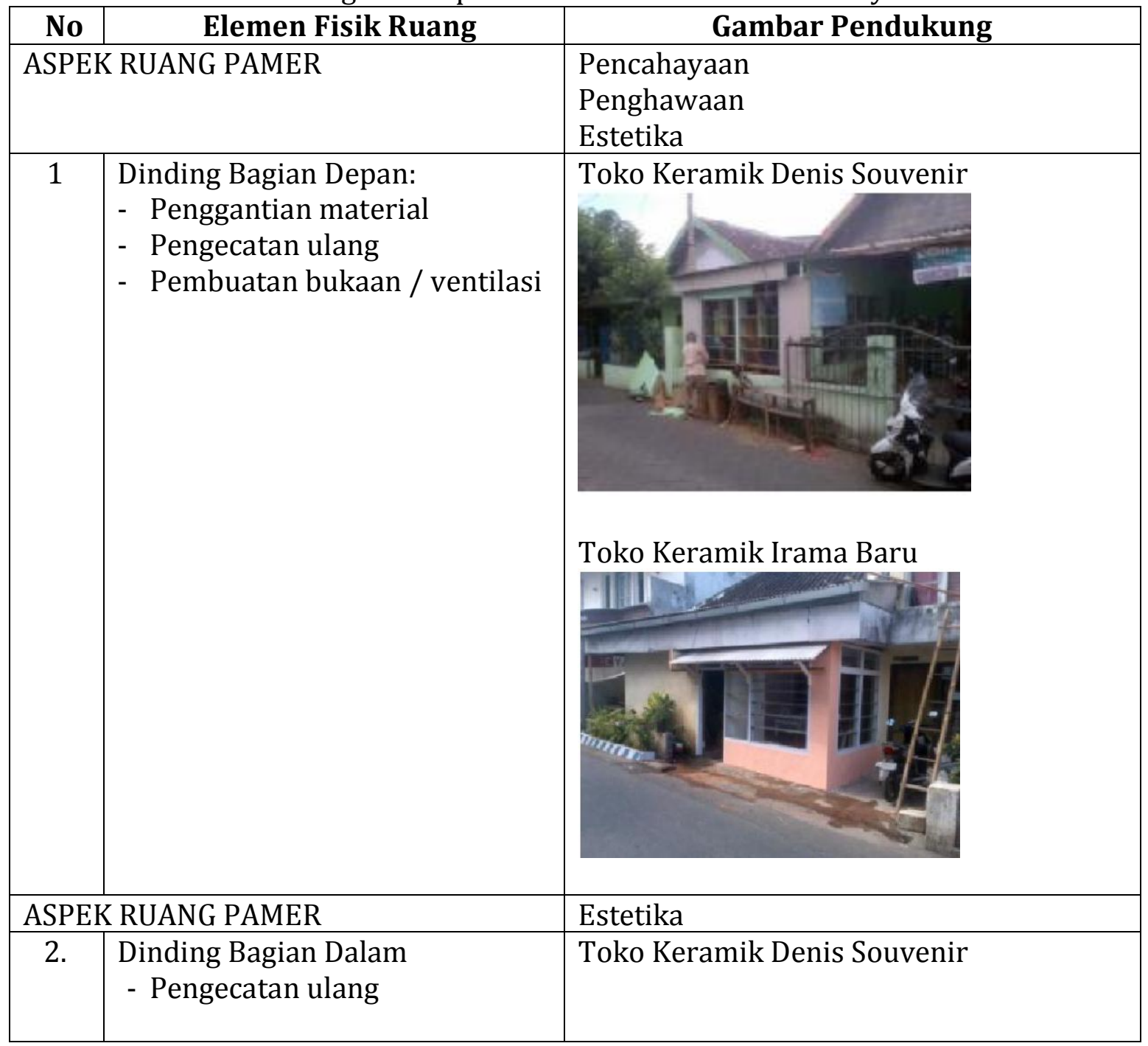




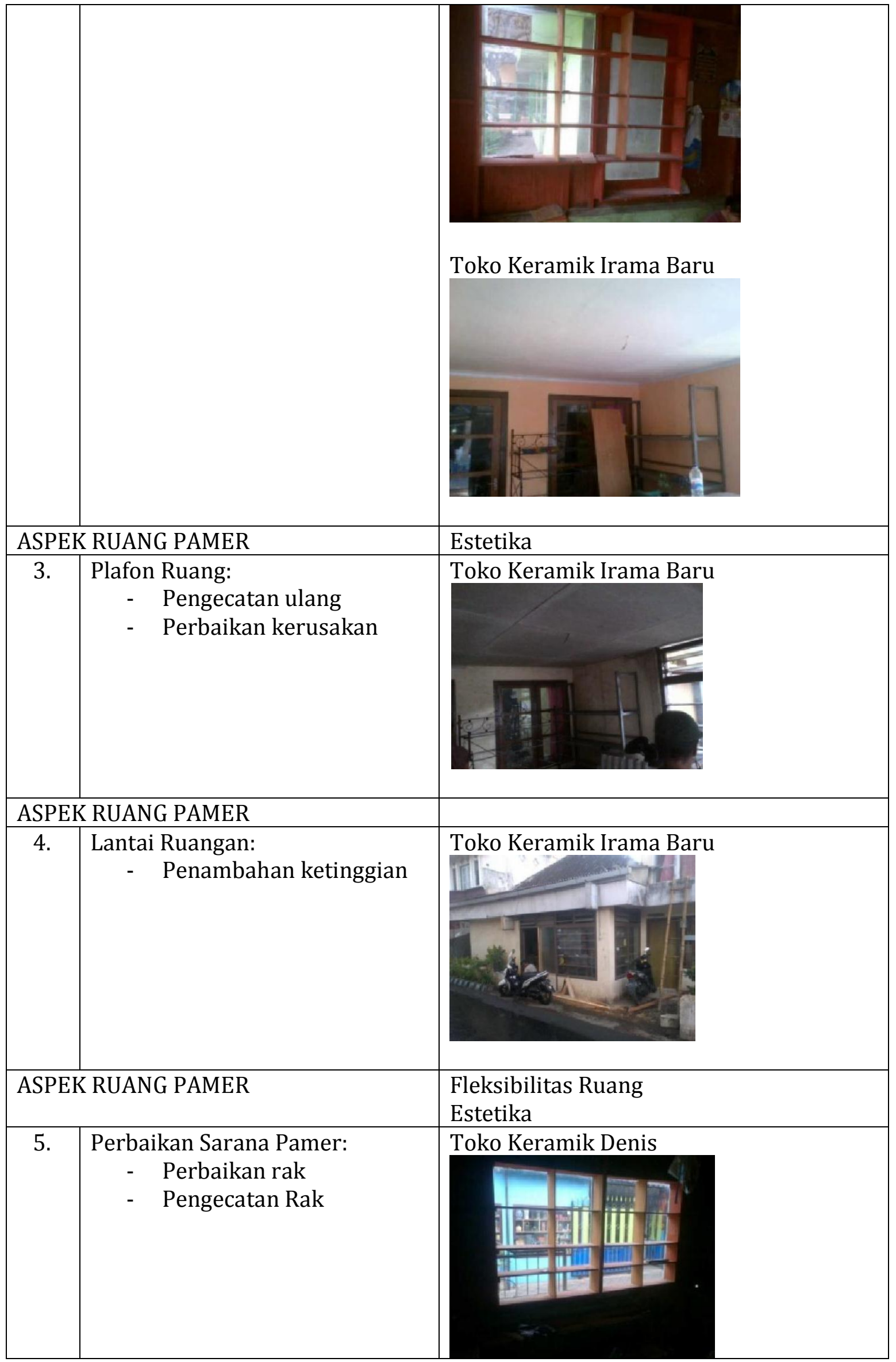




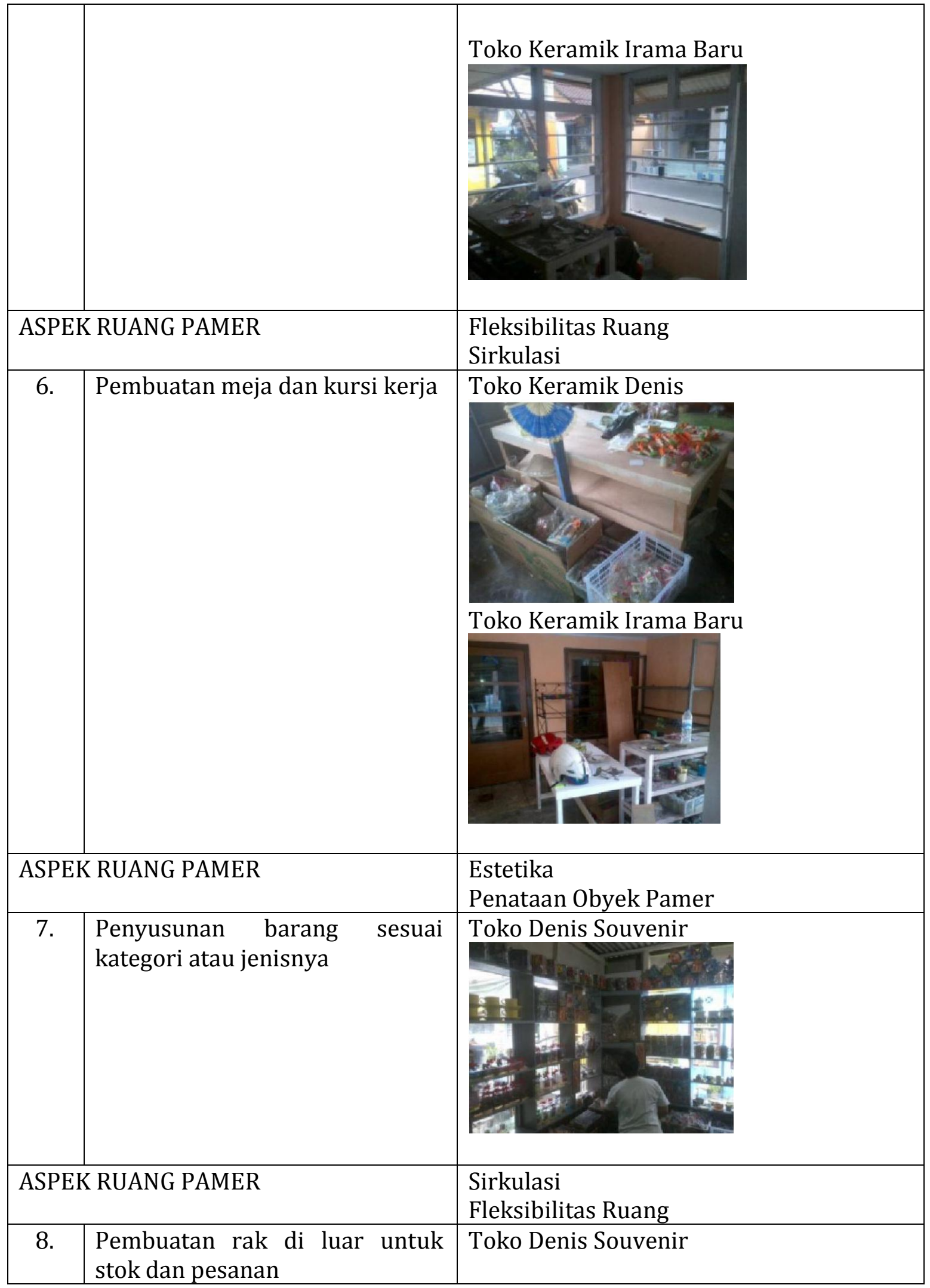




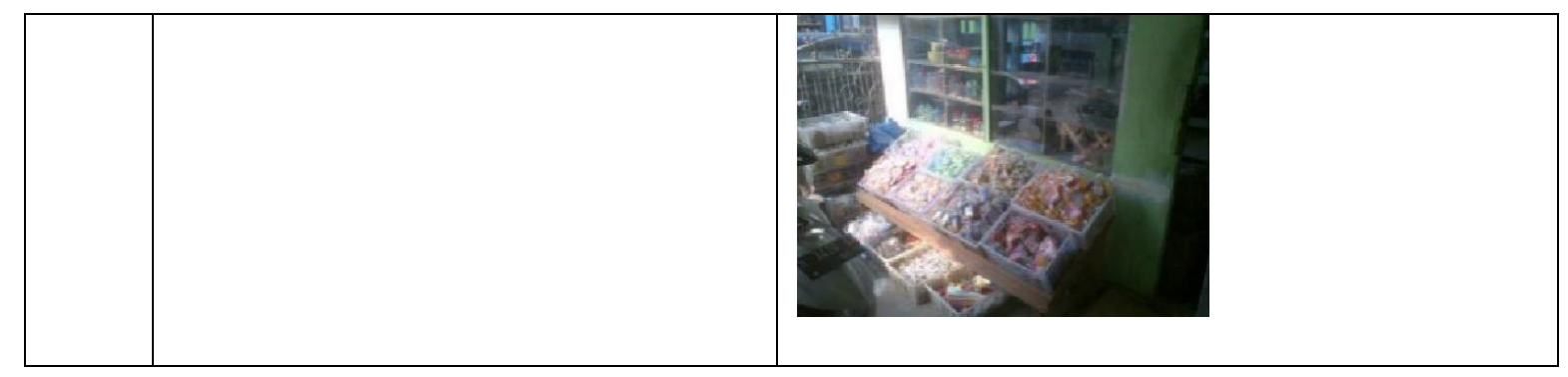

5. Kesimpulan

Kesimpulan yang dapat diambil dari kegiatan ini adalah:

a. Penataan ruang pamer kerajinan keramik sesuai dengan zoning kegiatan yaitu zona ruang pamer dan zona penyimpanan

b. Penataan ruang pamer yang fleksibel, sehingga sewaktu-waktu dapat diubah dengan cukup mudah sesuai dengan kondisi

c. Penataan ruang pamer dengan sirkulasi yang nyaman baik bagi pengrajin maupun pengunjung

d. Penataan ruang pamer dengan pencahayaan yang maksimal sehingga pengunjung dapat menikmati secara visual barang yang dipamerkan dengan nyaman

e. Dimensi zona ruang dalam ruang pamer yang sesuai dengan ruang gerak tiap aktivitas

f. Penataan objek pamer yang menarik dengan penyediaan perabot yang mendukung

g. Desain ruang pamer yang multifungsi (karena harus mewadahi aktivitas penjualan sekaligus produksi (tahap finishing)) memerlukan berbagai pertimbangan terutama aspek fleksibilitas

\section{Daftar Pustaka}

Ching, Francis DK. 2007. Architecture: Form, Space \& Order, 3rd ed. John Wiley, Hoboken.

De Chiara, J. \& Callender, J.H. 1980. Time Saver Standarts for Building Types. New York: Mc Graw-Hill Inc.

Dean D. 1996. Museum Exhibition: Theory and Practice. London:Routledge.

Neufert, E . 2012. Architect's Data, 4 edition.

New York:John Wiley \& Sons.

Santosa, JT, Ema YT, Triandriani M. 2012. Model Penataan Ruang Rumah Produktif untuk Peningkatan Kegiatan Ekonomi Industri Keramik Rakyat di Dinoyo, Malang. Laporan Penelitian Hibah Bersaing Institusi Universitas Brawijaya. Unpublished 